\title{
Biosynthesis of Multi-component Polyhydroxyalkanoates by the Bacterium Wautersia Eutropha
}

\author{
Tatiana G. Volova ${ }^{a, b}$, Galina S. Kalacheva ${ }^{a *}$ \\ and Alexander Steinbüchel ${ }^{\mathrm{c}}$ \\ anstitute of Biophysics of Siberian Branch of Russian Academy of Sciences, \\ Akademgorodok, Krasnoyarsk, 660036 Russia \\ ${ }^{b}$ Siberian Federal University, Svobodny av. 79, Krasnoyarsk, 660041 Russia \\ ' Institute of Molecular Microbiology and Biotechnology, \\ Westfalische Wilhelms-Universitat Munster, \\ Corrensstrasse 3, D-48149 Germany ${ }^{1}$
}

Received 1.09.2007, received in revised form 1.12.2007, accepted 15.01.2008

The study addresses the effect of different conditions of carbon nutrition on synthesis of polyhydroxyalkanoates by the bacterium Wautersia eutropha. In experiments with two wild-type strains (H16 and B5786) it has been first found that under mixotrophic growth conditions - CO2 + co-substrate (alkanoic acids) - bacteria can synthesize multi-component PHAs, consisting of short- and medium-chainlength monomers with carbon chains containing 4 to 8 atoms. It has been shown that PHA composition is determined by the type of the co-substrate. Fatty acids with odd number of carbons induce bacteria to synthesize four-and five-component PHAs with hydroxybutyrate, hydroxyvalerate, and hydroxyhexanoate as major monomers and hydroxyhexanoate and hydroxyoctanoate as minor, occasionally occurring, ones. Fatty acids with even number of carbons induce synthesis of not only their respective monomers (hydroxyhexanoate and hydroxyoctanoate) but also hydroxyvalerate, making possible synthesis of four-component PHAs, containing hydroxybutyrate and hydroxyhexanoate as major components (up to $18 \mathrm{~mol} \%)$. A family of short- and medium-chain-length four-and five-component PHAs has been synthesized and their physicochemical properties examined.

Keywords: Wautersia eutropha, autotrophic and mixotrophic growth, multi-component polyhydroxyalkanoates.

\section{Introduction}

Much consideration has been given recently to synthesis and investigation of polymers based on derivatives of carbonic acids. Among biodegradable polyesters, such as polylactides and polyglycolides, a special place is occupied by polyhydroxyalkanoates (PHAs) - polyesters of microbial origin. The main advantage of
PHAs is feasibility of synthesizing variously composed polymers, i.e. polymers with different physicochemical properties. This, however, requires fundamental knowledge about mechanisms of synthesis of a specifically composed PHA and about the relationship between the chemical structure of a polymer and its physicochemical properties. Among widespread

Corresponding author E-mail address: kalach@ibp.ru

(c) Siberian Federal University. All rights reserved 
PHAs are polyesters of various chemical structures, from high-crystallinity thermoplastic polymers to thermo labile rubber-like elastomers. PHAs can be divided into three groups: shortchain-length PHAs $\left(\mathrm{PHA}_{\mathrm{SCL}}\right)$, medium-chainlength PHAs $\left(\mathrm{PHA}_{\mathrm{MCL}}\right)$, and long-chain-length PHAs $\left(\mathrm{PHA}_{\mathrm{LCL}}\right.$ ). $\mathrm{PHA}_{\mathrm{SCL}}$ consist of $3-5$ carbon atoms $\left(\mathrm{C}_{3}-\mathrm{C}_{5}\right), \mathrm{PHA}_{\mathrm{MCL}}$ consist of $\mathrm{C}_{6}$ to $\mathrm{C}_{14}$, and PHA $_{\text {LCL }}$ consist of $\mathrm{C}_{17}$ to $\mathrm{C}_{18}$ and more carbons. The most extensively studied PHAs are shortchain-length ones - polyhydroxybutyrate (PHB) and hydroxybutyrate (HB) - hydroxyvalerate (HV) copolymers (PHB/PHV). Active studies of $\mathrm{PHA}_{\mathrm{MCL}}$ and $\mathrm{PHA}_{\mathrm{LCL}}$ were started quite recently and there are still very few data on producers capable of synthesizing multi-component PHAs, consisting of short- and medium-chain-length monomers $\left(\mathrm{PHA}_{\mathrm{SCL}+\mathrm{MCL}}\right)$.

Over 300 various PHA producers have been described, but just a few have been found to be able to synthesize $\mathrm{PHA}_{\mathrm{SCL}+\mathrm{MCL}}$. These are such wild-type strains as Pseudomonas sp. A33, which synthesizes $\mathrm{HB}$ copolymers with various monomers, from $\mathrm{C}_{12}$ to $\mathrm{C}_{16}$ (Lee et al., 1995); Pseudomonas putida GPo-1, which synthesizes medium-chain-length PHAs of various compositions (Hartmann et al., 2004); Thiococcus pfennigii, Aeromonas hydrophila, Aeromonas caviae, and Ectothiorhodospira shaposhnikovii, which synthesize HB-hydroxyhexanoate ( $\mathrm{HHx}$ ) copolymers (Liebergesell et al., 1993; Doi et al., 1995; Chen et al., 2001; Qiu et al., 2004; Zhang et al., 2004; Han et al., 2005); Aeromonas punctata and Wautersia eutropha (formerly known as Ralstonia eutropha (Vaneechoutte et al., 2004), which synthesize PHAs with carbon chains containing 4 to 8 carbon atoms (Liebergesell et al., 1991; 1993; Volova et al., 1996; 1998). Genetically modified producers of $\mathrm{PHA}_{\mathrm{SCL}+\mathrm{MCL}}$ have also been constructed: genetically engineered Pseudomonas sp. harboring PHA-synthesis genes from Ralstonia (Fukui and Doi, 1998); $R$. eutropha harboring Pseudomonas synthase gene; E.coli harboring PHA-synthesis genes from Aeromonas and Ralstonia, which synthesize HB-HHx copolymers (Qiu et al., 2004, 2006); R. eutropha harboring Pseudomonas fluorescens GK-13 synthase genes, which accumulates PHAs consisting of monomers of carbon numbers ranging from 4 to 12 atoms (Noda et al., 2005); W. eutropha harboring Pseudomonas sp. 61-3 genes, which synthesizes HB-hydroxyoctanoate (HO) copolymers (Delamarre and Batt, 2006).

Synthesis of multi-component PHAs requires specific conditions of carbon nutrition. As a rule, medium- and long-chain-length PHAs are synthesized using complex carbon substrates that contain the main carbon substrate and hydrocarbon acid salts with carbon chains of various lengths (6 to 9 atoms and longer) as co-substrates.

The bacterium Wautersia eutropha is one of the most promising PHA producing organisms: it can synthesize polymers of various chemical structures, mainly $\mathrm{PHA}_{\mathrm{SCL}}$, and give high polymer yields (up to $80-90 \%$ ), utilizing a wide range of substrates - hydrogen - carbon dioxide mixtures, sugars, organic acids, alcohols, industrial and agricultural wastes (Tanaka et al., 1995; Fukui, Doi, 1998; Bormann and Roth, 1999; Ishizaki et al., 2001; Volova et al., 2002). The predominant monomer in the PHAs of Wautersia is HB; another monomer, $\mathrm{HV}$, can amount to $80-90 \mathrm{~mol} \%$ under specified conditions (Doi et al., 1998); however, reported levels of HHx and HO do not exceed 12 mol\% (Liebergesell et al., 1991; Dennis et al., 1998; Antonio et al., 2000; Green et al., 2002).

The purpose of the study was to investigate and compare accumulation of $\mathrm{PHA}_{\mathrm{SCL}+\mathrm{MCL}}$ by Wautersia eutropha strains H16 and B5786 under different conditions of carbon nutrition and analyze their chemical structure. 


\section{Methods}

The objects of the study were two strains of Wautersia eutropha - H16 and B5786. Strain H16, isolated by Professor H. Schlegel, is the most heavily investigated strain of Wautersia eutropha in EC states and strain B5786, a fastgrowing variant of $W$. eutropha Z1 (Stasishina and Volova, 1992), isolated by Academician G.A. Zavarzin's research team (Zavarzin, 1972) - in Russia. Bacteria were batch-cultured under strictly aseptic conditions using Schlegel's method (Schlegel et al., 1961) in 1-1 flasks filled to 50\% of their volume, on a thermostatic shaker; we used our procedure promoting PHA synthesis, which was described elsewhere (Volova et al., 1992). Under autotrophic conditions, the carbon source was $\mathrm{CO}_{2}$ and under heterotrophic conditions - fructose. Bacteria were cultured in standard Schlegel mineral salts medium (Schlegel et al., 1961) deficient in NH4Cl. To induce synthesis of multi-component polymers, the culture medium was supplemented with such co-substrates as salts of alkanoic acids (valerate, hexanoate, heptanoate, and octanoate) (Sigma reagents) at concentrations of 0.5-2.0 g/l. Hydrocarbon acids were extracted with hexane from acidulous samples of the culture medium and their concentrations were measured by gas chromatography. Corresponding alkanoic acids were used as internal standards.

Accumulation of the biomass in the culture was monitored by measuring the dry matter weight and optical density of the culture. Dry biomass samples were subjected to methanolysis and the total polymer content of the biomass and monomer compositions were determined by the chromatography of methyl esters of fatty acids on a GCD-Plus gas chromatograph-mass spectrometer (Hewlett Packard, USA) (Volova et al., 1998). Polymer and lipids were extracted from biomass with a chloroform-ethanol mixture $(2: 1 \mathrm{v} / \mathrm{v})$ and then the polymer was separated from lipids by precipitation with hexane. The chemical structure of the extracted and twice precipitated polymer was analyzed in a similar manner, using the chromatograph-mass spectrometer. Monomers were identified by their retention time and mass spectra. PHA films prepared by the solution casting technique were used to investigate temperature characteristics and crystallinity of PHAs. Temperature characteristics of the polymers were measured with a derivatograph (MOM, Hungary), which simultaneously registered curves of differential thermal analysis (DTA) and performed thermogravimetry (TG) and derivative thermogravimetry (DTG). $0.1-\mathrm{mm}$ thick PHA samples of various compositions were placed into platinum crucibles. The polymers were analyzed in the inert gas medium; the heating was conducted at a rate of $5^{\circ} \mathrm{C} / \mathrm{min}$, from 20 to $300^{\circ} \mathrm{C}$. Melting points and temperatures for the onset of decomposition were determined as temperatures of heat absorption peaks of the corresponding endothermic effects. The error of derivatogram-based determination of endothermic effect temperatures was $\pm 1^{\circ} \mathrm{C}$. The $\mathrm{X}$-ray structure analysis was conducted using a D8 ADANCE X-ray spectrometer (Bruker, Germany) (graphite monochromator on a reflected beam). To determine the degree of crystallinity, $\mathrm{C}_{\mathrm{x}}$, spectra were taken in a scan-step mode, with step $0.04^{\circ}$, exposure time 2 ', to measure intensity at point. The operating mode of the instrument was $40 \mathrm{kV} \times 40 \mu \mathrm{A}$.

\section{Results and Discussion}

In the autotrophic culture, when bacteria were grown on a sole carbon substrate $\left(\mathrm{CO}_{2}\right)$ and their growth was limited by nitrogen deficiency, polymer yields produced by the both strains were almost identical. After $48 \mathrm{~h}$ of fermentation, strains $\mathrm{H} 16$ and B5786 yielded 5.8 and $6.1 \mathrm{~g} / 1$ of biomass, respectively, the final polymer concentration being 63.0 and $61.4 \%$. In the polymer synthesized by 
both strains, the predominant fraction was that of HB (96.6 - $99.2 \mathrm{~mol} \%)$; minor components were HV (0.6-2.8 mol\%) and HHx (0.2-0.7 mol\%).

Data on bacterial growth and PHA synthesis on mixed carbon substrates $\left(\mathrm{CO}_{2}+\right.$ valerate, hexanoate, etc.) in $\mathrm{H} 16$ and B5786 cultures are shown in Fig. 1.

Synthesis of multi-component PHAs is a very complicated biotechnological task. To cope with it, one has to take into account a number of factors. First, fast-growing bacterial cultures, except Alcaligenes latus, cannot produce high PHA yields, and special growth conditions must be created to attain high polymer yields along with high total biomass production. Second, monomers differing in the number of carbon atoms cannot be incorporated into the polymer at the same rate, thus, in microorganism culture, fractions of monomers in a PHA are unstable. Third, hydrocarbon acids, which are used as co-substrates, are toxic to most microbial cultures, so it is essential to determine maximal permissible concentrations of every acid for every PHA producer. Thus, production of multi-component PHAs in dense cultures, with high intracellular content of PHA (over 50-60\%) containing long-chain-length monomers as the major ones, is rather problematic.

In this work we cultured bacteria in accordance with the procedure that we had developed before [28], which took into account that monomers with different number of carbon atoms were incorporated into the polymer at various rates and that fatty acid salts added to the culture as co-substrates were toxic to bacteria. Dynamics of synthesis and composition of PHAs produced by the studied strains varied depending upon the length of the carbon chain of the added co-substrate (Fig. 1).

After the 12-h culture was supplemented with valerate (at $\mathrm{X}$ 2.7-2.8 $\mathrm{g} / \mathrm{l}$ and polymer content 22\%) (Fig. 1, $\mathrm{C}_{5}$ ), the biomass yields of both cultures increased to $4.1-4.8 \mathrm{~g} / 1$ and polymer yields to $48.9-63.8 \%$. At the end of the experiment, intracellular polymer content exceeded $90 \%$. Both strains synthesized 4- and 5-component polymers. The major monomers were $\mathrm{HB}$ and $\mathrm{HV}$ and the minor ones - HHx, HHp, and HO. However, HHx and $\mathrm{HO}$ were not regularly registered. Percentages of PHA fractions varied depending on how much time had passed after addition of a co-substrate (Fig. 1, $\mathrm{C}_{5}$ ). The composition of recovered and purified PHAs (36-h and 48-h cultures) was the same as that of biomass samples (Table 1). By varying amounts of added valerate and time of the subsequent culture, we managed to induce both strains to synthesize PHAs containing up to 85 mol\% HV (Table 2).

Bacteria grown on the $\mathrm{CO}_{2}$ - heptanoic acid mixed substrate (Fig. 1, $\mathrm{C}_{7}$ ) synthesized polymers that mostly consisted of HV and HB. HHp fractions were insignificant (below 2 mol\%) and $\mathrm{HHx}$ and HO inclusions were small and unstable (Table 1). Qualitative composition of polymer samples was the same as that of biomass samples (Table 1) and varied depending on culture duration. Polymer yield was similar to that in the above-described experiment with valerate (over $90 \%$ ).

When the strains were grown on mixtures of $\mathrm{CO}_{2}$ and salts of fatty acids with even number of carbons, they synthesized multi-component PHAs of other compositions.

With hexanoate as a co-substrate, both strains synthesized PHAs with $\mathrm{HB}$ and the medium-chainlength $\mathrm{HHx}$ as the major fractions (Fig. 1, $\mathrm{C}_{6}$ ). Polymer accumulation pattern was characteristic of autotrophic culture, and the polymer had the maximal HHx content (up to $13 \mathrm{~mol} \%$ ) in $24 \mathrm{~h}$ after the addition of the fatty acid. By that time, intracellular polymer content had exceeded $50 \%$. In addition to $\mathrm{HHx}$, the polymers also contained HO (0.6-0.8 mol\%) and HV (2.05-3.74 $\mathrm{mol} \%$ ). At the end of the experiment, intracellular polymer concentration reached $70 \%$; the $\mathrm{HHx}$ fraction decreased to $11 \mathrm{~mol} \%$, the $\mathrm{HV}$ fraction 

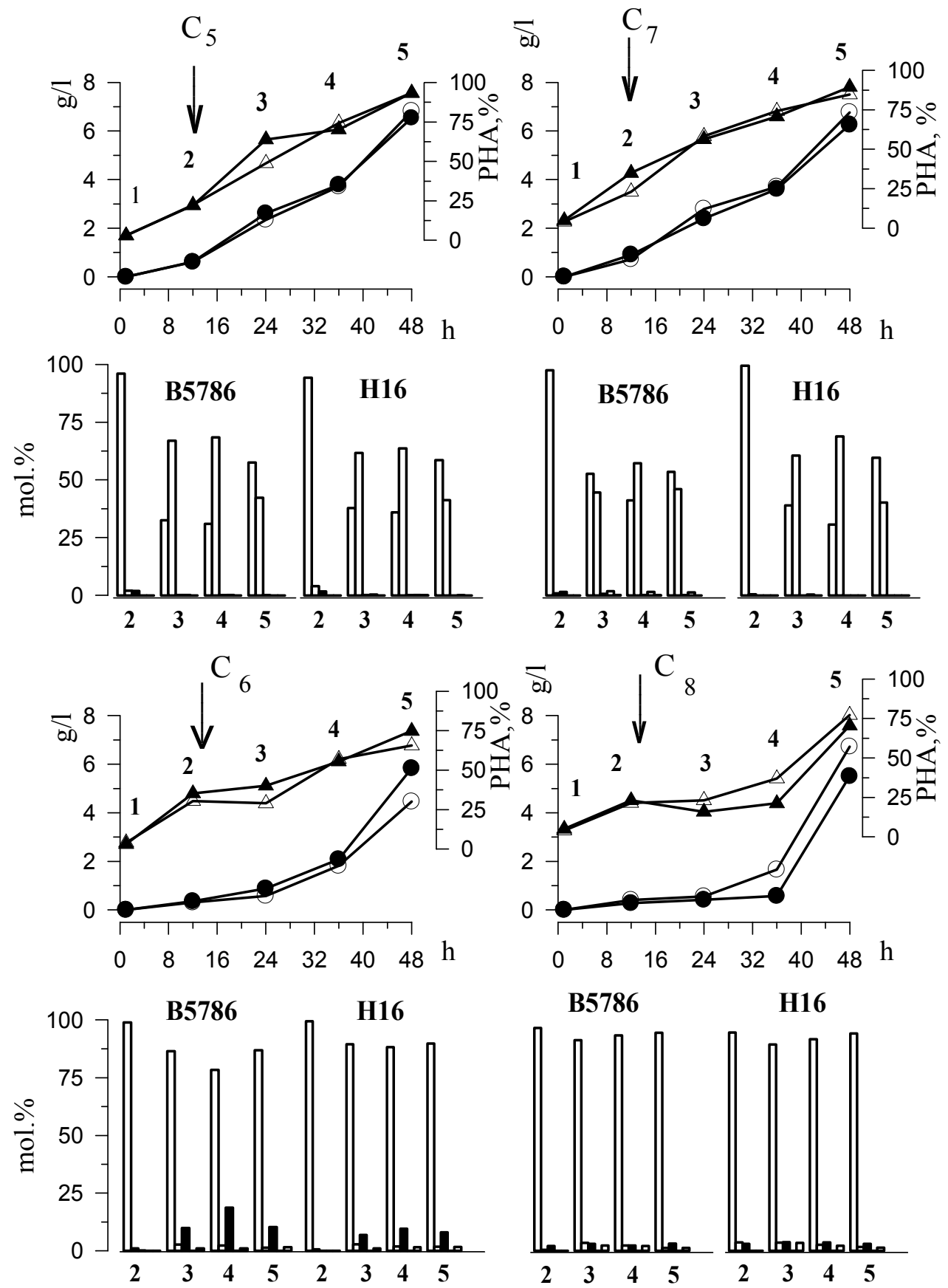

Fig. 1. Dynamics of PHA synthesis and composition for two strains of Wautersia eutropha, B5786 and H16, grown under specific conditions.

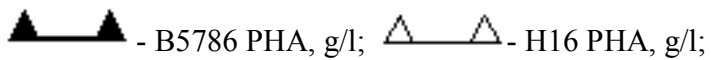

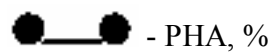

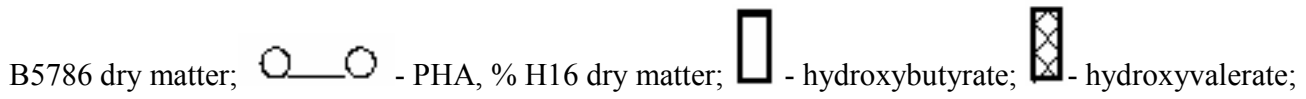
- hydroxyhexanoate; $\square_{\text {-hydroxyheptanoate; }} \square_{\text {- hydroxyoctanoate. 1, 2, 3, 4, 5- sampling points. }}$ 
Table 1. Composition of polymers recovered from two strains of Wautersia eutropha grown in autotrophic, mixotrophic, and heterotrophic cultures supplemented with acids with even and odd number of carbons (mol\%)

\begin{tabular}{|c|c|c|c|c|c|c|c|c|c|c|c|}
\hline \multirow[t]{2}{*}{ Supplement } & \multirow{2}{*}{$\begin{array}{l}\text { Culture } \\
\text { duration }\end{array}$} & \multicolumn{5}{|c|}{ B5786 } & \multicolumn{5}{|c|}{ H16 } \\
\hline & & HB & $\mathrm{HV}$ & $\mathrm{HHx}$ & HHp & $\mathrm{HO}$ & $\mathrm{HB}$ & HV & HHx & $\mathrm{HHp}$ & $\mathrm{HO}$ \\
\hline $\mathrm{CO}_{2}$ & 48 & 96.60 & 2.80 & 0.60 & ND* & ND & 97.60 & 1.70 & 0.70 & $\mathrm{ND}$ & ND \\
\hline $\mathrm{CO}_{2}+\mathrm{C}_{5}$ & 36 & 31.22 & 68.40 & 0.13 & 0.20 & 0.04 & 36.01 & 63.64 & 0.12 & 0.21 & 0.02 \\
\hline $\mathrm{CO}_{2}+\mathrm{C}_{5}$ & 48 & 6.65 & 41.71 & 0.05 & 0.04 & ND & 58.15 & 41.71 & 0.08 & 0.06 & itr. \\
\hline $\mathrm{CO}_{2}+\mathrm{C}_{7}$ & 36 & 1.94 & 56.30 & 0.71 & 1.01 & 0.05 & 36.10 & 63.52 & 0.07 & 0.28 & 0.03 \\
\hline $\mathrm{CO}_{2}+\mathrm{C}_{7}$ & 48 & 2.25 & 47.33 & 0.09 & 0.33 & ND & 59.36 & 40.48 & 0.06 & 0.10 & ND \\
\hline $\mathrm{CO}_{2}+\mathrm{C}_{6}$ & 36 & 1.81 & 3.69 & 13.76 & ND & 0.75 & 81.86 & 3.74 & 13.68 & ND & 0.72 \\
\hline $\mathrm{CO}_{2}+\mathrm{C}_{6}$ & 48 & 5.89 & 2.05 & 11.44 & ND & 0.62 & 85.60 & 2.76 & 10.84 & ND & 0.84 \\
\hline $\mathrm{CO}_{2}+\mathrm{C}_{8}$ & 36 & 2.14 & 24.80 & 1.11 & 0.23 & 0.72 & 86.07 & 9.32 & 2.59 & 0.04 & 1.99 \\
\hline $\mathrm{CO}_{2}+\mathrm{C}_{8}$ & 48 & 1.70 & 4.59 & 2.55 & ND & 1.17 & 93.31 & 3.34 & 2.38 & ND & 0.97 \\
\hline Fructose & 36 & 8.16 & 21.03 & 0.81 & ND & ND & 73.17 & 26.74 & 0.09 & ND & ND \\
\hline Fructo & 36 & 7.06 & 1.54 & 1.40 & ND & ND & 97.55 & 1.25 & 1.20 & ND & ND \\
\hline Fructose $+\mathrm{C}_{8}$ & 36 & 98.72 & 0.77 & 0.32 & ND & ND & 97.63 & 1.17 & 1.20 & ND & ND \\
\hline
\end{tabular}

*ND - not detected; tr. - trace amounts

Table 2. Chemical structure and properties of multi-component polymers of Wautersia eutropha

\begin{tabular}{|c|c|c|c|c|c|c|c|c|}
\hline Sample No. & \multicolumn{5}{|c|}{ PHA composition, $\mathrm{mol} \%$} & \multicolumn{3}{c|}{ PHA properties } \\
\cline { 2 - 9 } & $\mathrm{HB}$ & $\mathrm{HV}$ & $\mathrm{HHx}$ & $\mathrm{HHp}$ & $\mathrm{HO}$ & $\mathrm{C}_{\mathrm{x}}, \%$ & $\mathrm{~T}_{\mathrm{m}},{ }^{\circ} \mathrm{C}$ & $\mathrm{T}_{\mathrm{d}},{ }^{\circ} \mathrm{C}$ \\
\hline 1 & 11.22 & 88.46 & 0.13 & 0.16 & 0.04 & 49 & 146 & 210 \\
\hline 2 & 36.01 & 63.64 & 0.12 & 0.21 & 0.02 & 51 & 150 & 213 \\
\hline 3 & 41.94 & 56.30 & 0.71 & 0.98 & 0.06 & 48 & 153 & 230 \\
\hline 4 & 52.25 & 47.33 & 0.09 & 0.33 & $\mathrm{ND}$ & 46 & 158 & 234 \\
\hline 5 & 79.61 & 1.50 & 18.03 & $\mathrm{ND}$ & 0.85 & 53 & 155 & 253 \\
\hline 6 & 81.81 & 3.69 & 13.76 & $\mathrm{ND}$ & 0.74 & 60 & 156 & 253 \\
\hline 7 & 83.38 & 4.47 & 11.63 & $\mathrm{ND}$ & 0.52 & 62 & 157 & 257 \\
\hline 8 & 90.63 & 2.29 & 6.52 & $\mathrm{ND}$ & 0.56 & 65 & 159 & 256 \\
\hline 9 & 91.70 & 4.59 & 2.55 & $\mathrm{ND}$ & 1.17 & 74 & 163 & 265 \\
\hline 10 & 99.76 & 0.24 & tr. & ND & ND & 74 & 168 & 268 \\
\hline
\end{tabular}

to $2.0-2.8 \mathrm{~mol} \%$, while the $\mathrm{HO}$ content remained unchanged $-0.6-0.8 \mathrm{~mol} \%$. The compositions of the recovered and purified polymers synthesized by the two strains were identical and did not differ from those of biomass samples (Table 1). The increase in HO may indicate that monomer precursors can be formed in the cell not only due to fatty acid oxidation but also in the course of acyl chain elongation.

Addition of octanoate, which is more toxic for the strains, inhibited culture growth and polymer synthesis even at concentration $0.5 \mathrm{~g} / 1$ (Fig. 1, $\mathrm{C}_{8}$ ). When octanoate concentration in the culture medium decreased, biomass growth and polymer synthesis were resumed. At the end of the experiment intracellular PHA concentration was $70-77 \%$ and biomass yield $-7.8-8.7 \mathrm{~g} / \mathrm{l}$. In this experiment, qualitative composition of the polymers recovered in $12 \mathrm{~h}$ after addition of octanoic acid was significantly different from that of biomass samples: the polymers contained enhanced HV percentages ( $24.8 \mathrm{~mol} \%$ for B5786 and $9.32 \mathrm{~mol} \%$ for H16), an HHp fraction was present, and the HO fraction was smaller (2.05$2.21 \mathrm{~mol} \%$ in biomass polymer vs. 0.72-1.99 mol\% in the recovered polymer). At the end of the experiment, compositions of the recovered polymers and biomass samples were similar: HB -91.7 - 93.3; HV - 4.6 - 3.3; HHX - 2.55 - 3.34; 
and $\mathrm{HO}-1.0-1.2 \mathrm{~mol} \%$, for B5786 and $\mathrm{H} 16$, respectively (Table 1).

Thus, in experiments with two strains it was shown for the first time that multi-component PHAs, containing short- and medium-chain-length monomers, can be synthesized on a complex carbon substrate $\left(\mathrm{CO}_{2}+\mathrm{a}\right.$ fatty acid). In addition to PHAs with hydroxybutyrate and hydroxyvalerate as predominant monomers, we also prepared PHA samples that contained hydroxyhexanoate as a major component.

When the same culture procedure was used to grow bacteria on heterotrophic substrate (fructose + a fatty acid), both strains synthesized three-component PHAs that contained more than $97 \mathrm{~mol} \% \mathrm{HB}$ and minor fractions of $\mathrm{HV}$ and $\mathrm{HHx}$, no matter what co-substrate was used (Table 1). One exception was the experiment with valerate as a co-substrate: a three-component PHA with
$\mathrm{HV}$ amounting to $26 \mathrm{~mol} \%$ and $\mathrm{HHx}$ as a minor component was synthesized.

To illustrate, Fig. 2 shows two chromatograms of PHAs recovered from H16 culture with heptanoate and B5786 culture with octanoate and mass spectra of all the 5 monomers, which confirm their identity.

By culturing bacteria autotrophically and varying amounts of added acids with even and odd number of carbons and fermentation duration, we managed to obtain a family of short-and mediumchain-length PHAs, whose physicochemical properties are presented in Table 2. These results confirm our earlier evidence that the presence of the HV fractions is a significant factor in redistribution of the amorphous and crystalline phases in the polymer, reducing the degree of crystallinity. However, these changers are only caused by HV fractions from a few mol\% to 25 -

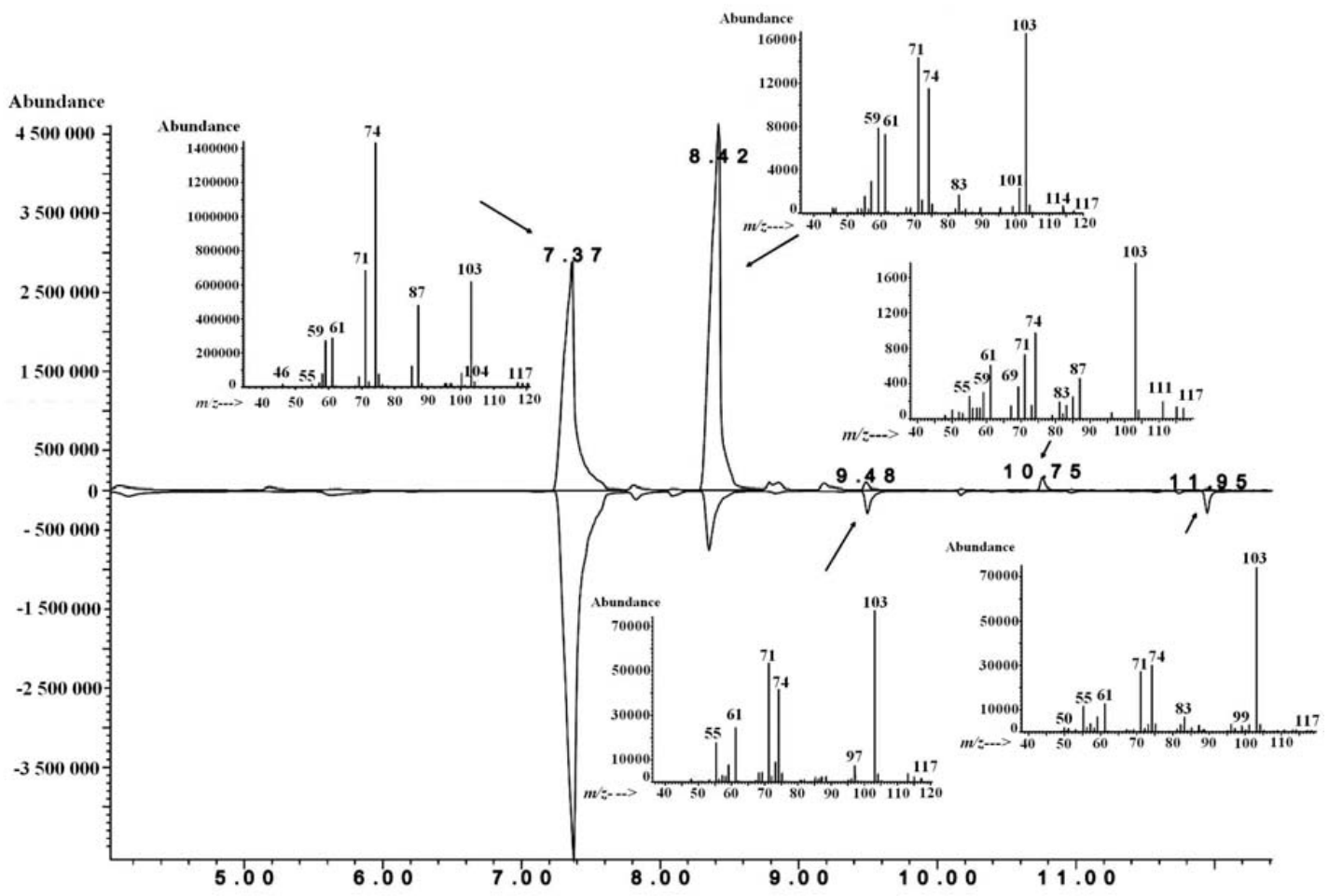

Fig. 2. Ion chromatograms of polymers extracted from Wautersia eutropha H16 biomass supplemented with heptanoate (above) and Wautersia eutropha B5786 supplemented with octanoate (mirror below) and mass spectra of respective monomers $-\mathrm{HB}$ with retention time $7.37, \mathrm{HV}-8.42, \mathrm{HHx}-9.48, \mathrm{HHp}-10.75, \mathrm{HO}-11.95$ 
$30 \mathrm{~mol} \%$, the presence of $\mathrm{HV}$ over $50 \mathrm{~mol} \%$ does not cause a change in Cx. Larger HV fractions influenced temperature characteristics of the polymer, and the most significant influence was observed when the HV fraction exceeded 35-40 mol\%. Minor fractions - HHp (0.98 mol\%) and HO (1.2 mol\%) - did not affect the degree of crystallinity of the polymer.

It was particularly interesting for us to investigate our first samples of PHAs that contained as major fractions not only HB but also hydroxyhexanoate (2 to $18 \mathrm{~mol} \%$ ). Analysis of Xray spectra revealed a clear relationship between the degree of crystallinity of a PHA and its HHx percentage (Table 2). As the HHx fraction grew, the degree of crystallinity of the PHA steadily decreased. Hence, similarly to HV, presence of HHx in the polymer decreases its crystallinity and improves its processability. Temperature characteristics of the PHA also changed as the HHx percentage increased. As the HHx fraction increased (within the studied range, from a few mol\% to $18 \mathrm{~mol} \%$ ), both $\mathrm{Tm}$ and $\mathrm{Td}$ of the PHA decreased, but no difference between the melting point and the temperature for the onset of decomposition was registered.

Analysis of the results obtained first of all shows identical direction of PHA synthesis by the H16 and B5786 strains of $W$. eutropha. The accepted notion (Wei et al., 2001) is that qualitative composition of a PHA is determined by substrate specificity of its PHA synthase (polymerase), a key enzyme of the PHA cycle. Analysis of amino acid sequences of the $W$. eutropha B5786 synthase and comparison with the primary structure of the W. eutropha H16 synthase showed a very high homology (99\%) and revealed quite insignificant differences in the primary structures of the synthases of these two strains, which are located in the short non-identical fragment of the Cterminal domain, between the 561 and 572 amino acid sequences (Kozhevnikov et al., 2005).
It has been reported that $W$. eutropha can successfully produce not only PHB but also a copolymer - poly(HB-co-HV) (Doi et al., 1998; Shang et al., 2004). Incorporation of monomers of carbon numbers over five was observed only under inhibition of $\beta$-oxidation of fatty acids (Green et al., 2002) or in specially constructed strains (Dennis et al., 1998; Antonio et al., 2000). Our results indicate that under autotrophic conditions, the study strains can synthesize a three-component PHA with minor HV and HHx fractions, even without added acids. Cultured mixotrophically $\left(\mathrm{CO}_{2}+\right.$ a fatty acid), both strains synthesize fourand five-component polymers, with $\mathrm{HB}, \mathrm{HV}$ or HHx as major monomers. The high HV percentage that we registered in experiments with fatty acids with odd number of carbons is a natural result, consistent with the literature data (Doi et al., 1998, Shang et al., 2004). However, large fractions of HHx in the polymer synthesized by Wautersia have not been reported in the literature, although this PHA type is of great interest to researchers. A producer of the HB/HHx copolymers - Aeromonas hydrophyla - has been isolated recently. The wild-type strain accumulates up to $45 \%$ poly(HB/ HHx), with the HHx fraction 10-13 mol\% (Qiu et al., 2004; Han et al., 2005; Qiu et al., 2006). Our results show that both of our study strains, when cultured mixotrophically, produce a polymer of a composition, which is not inferior in quality to the polymer of $A$. hydrophyla.

In summary, it can be concluded that in mixotrophic culture, fatty acids with odd number of carbons (valerate and heptanoate) induce H16 and B5786 to synthesize 4- and 5-component PHAs with hydroxybutyrate and hydroxyvalerate as major monomers and hydroxyhexanoate and hydroxyoctanoate as minor ones. Fatty acids with even number of carbons (hexanoate and octanoate) serve as substrates for synthesis of the respective monomers (hydroxyhexanoate and, to a lesser degree, hydroxyoctanoate) and induce 
incorporation of small hydroxyvalerate fractions into the PHA.

This study was financially supported by the Russian Ministry of Education and the U.S. Civilian Research \& Development Foundation
(CRDF and ME RF REC) (Grant (C) BP1MO2), and the Program for Interdisciplinary Projects of the Siberian Branch of the RAS (Project No. $24,54)$.

\section{References}

Antonio R.V., Steinbüchel A., Rehm B.H.A. (2000) Analysis of the in vivo substrate specificity of the PHA synthase from Ralstonia eutropha: formation of novel copolyesters in recombinant Escherichia coli. FEMS Microbiol. Lett. 182:111-117.

Bormann E.J., Roth M. (1999) The production of polyhydroxybutyrate by Methylobacterium rhodesianum and Ralstonia eutropha in media containing glycerol and casein hydrolysates. Biothechnol. Lett. 21:1059-1063.

Chen G.Q., Zhang G., Lee S.Y. (2001) Industrial production of poly(hydroxybutyrate-cohydroxyhexanoate). Appl. Microbiol. Biotechnol. 57:50-55.

Delamarre S.C. and Batt C.A. (2006) Comparative Study of Promoters for the Production of Polyhydroxyalkanoates in recombinant strains of Wautersia eutropha. Appl. Microbiol. Biotechnol. 71:668-679.

Dennis D., McCoy M., Stangl A., Valentin H.E., Wu Z.(1998)Formation of poly(3-hydroxybutyrateco-3-hydroxyhexanoate) by PHA synthase from Ralstonia eutropha. J. Biotechnol. 64:177-186.

Doi Y., Kitamure S., Abe H. (1995) Microbial synthesis and characterization of poly(3hydroxybutyrate-co-3-hydroxyhexanoate). Macromol. 28:4822-4828.

Doi Y., Tamaki A., Kunioka M., Soga K. (1998) Production of copolyesters of 3-hydroxybutyrate and 3-hydroxyvalerate by Alcaligenes eutrophus from butyric and pentanoic acids. Appl. Microbiol. Biotechnol. 28:330-334.

Fukui T., Doi Y. (1998) Efficient production of polyhydroxyalkanoates from plant oils by Alcaligenes eutrophus and its recombinant strain. Appl. Microbiol. Biotechnol. 49:333-336.

Green P.R., Kemper J., Schechtman L., Guo L., Satkowski M., Fiedler S., Steinbüchel A. and Rehm B.H.A. (2002) Formation of short chain length/medium length polyhydroxyalkanoate copolymers by fatty acid $\beta$-oxidation inhibited Ralstonia eutropha. Biomacromol. 3:208-213.

Han J., Qiu Y.-Z., Liu D.-C., Chen G.-Q. (2005) Engineered Aeromonas hydrophila for enhanced production of poly(3-hydroxybutyrate-co-3-hydroxyhexanoate) with alterable monomers composition. FEMS Microbiol Lett. 239:195-201.

Hartmann R., Hany R., Geiger T., Egli T., Witholt B., and Zinn M. (2004) Tailored biosynthesis of olefinic medium-chain-length poly[(R)-3-hydroxyalkanoates] in Pseudomonas putida GPo1 with improved thermal properties. Macromol. 70:6780-6785.

Ishizaki A., Tanaka K., Taga N. (2001) Microbial production of poly-D-3-hydroxybutyrate from CO2. Appl. Microbiol. Biotechnol. 57:6-12.

Kozhevnikov I.V., Volova T.G., Tran Hai, Steinbüchel A., and Volodina E.V. (2005) Cloning and molecular organization of the polyhydroxyalkanoate-synthase gene (phaC) from Ralstonia eutropha. 
Vestnik Krasnoyarskogo gosuniversiteta (Bulletin of the Krasnoyarsk State University) 5:214-223 (in Russian).

Lee E.L., Jendrossek D., Schirmer A., Choi C.V., Steinbüchel A. (1995) Biosynthesis of copolymers consisting of 3-hydroxybutyric acid and medium-chain-length 3-hydroxyalkanoik acids from 1,3-butandiol or from 3-hydroxybutyrate by Pseudomonas sp. A33. Appl. Microbiol. Biotechnol. 42:901-909.

Liebergesell M., Hustede E., Timm A., Steinbüchel A., Fuller R.C., Lenz R.W., and Schlegel H.G. (1991) Formation of poly(3-hydroxyalkanoates) by phototrophic and chemolithotrophic bacteria. Arch. Microbiol. 155: 416-421.

Liebergesell M., Mayer F., Steinbüchel A. (1993) Analysis of polyhydroxyalkanoic acidbiosynthetic genes of anoxygenic phototrophic bacteria reveals synthesis of a polyester exhibiting an unusual composition. Appl. Microbiol. Biotechnol. 40:292-300.

Noda I., Green P.R., Satkowski M.M., and Schechtman L.A. (2005) Preparation and properties of a novel class of polyhydroxyalkanoate copolymers. Biomacromol. 6:580-586.

Qiu Y.-Z., Ouyang S.-P., Shen Z., Wu Z., Chen G.-Q. (2004) Metabolic engineering for the production of copolyesters consisting of 3-hydrohybutyrate and 3-hydrohyhexanoate by Aeromonas hydrophila. Macromol. Bioscience 4:255-261.

Qiu Y.-Z., Han J., Chen G.-Q. (2006) Metabolic engineering of Aeromonas hydrophila for the enhanced production of poly(3-hydroxybutyrate-co-3-hydroxyhexanoate). Appl. Microbiol. Biotechnol. 69:537-542.

Schlegel H.G., Kaltwasser H., Gottschalk G. (1961) Ein Submersverfahren zur Kultur wasserstoffoxydierender Bakterien: wachstumphysiologische Untersuchungen. Arch. Mikrobiol. 38:209-222.

Shang L., Seong Chun Yim, Hyun Gyu Park, Ho Nam Chang (2004) Sequential feeding of glucose and valerate in a fed-batch culture of Ralstonia eutropha for production of poly(hydroxybutyrate-cohydroxyvalerate) with high 3-hydrohyvalerate fraction. Biotechnol. Prog. 20:140-144.

Stasishina G.N., Volova T.G. (1992) Shtamm bakterii Alcaligenes eutrophus B5786 - produtsent. (The producing strain of the bacteria Alcaligenes eutrophus B5786). RF Patent No. 2053292 (Priority of 08.01.1992). BI 1966. No. 1 (in Russian).

Tanaka K., Ishizaki A., Kanamaru T., Kawano T. (1995) Production of poly(D-3-hydroxybutyrate) from $\mathrm{CO}_{2}, \mathrm{H}_{2}$ and $\mathrm{O}_{2}$ by high cell density autotrophic cultivation of Alcaligenes eutrophus. Biotethnol. Bioeng. 45:268-275.

Vaneechoutte M., Kämpfer P., De Baere T., Falsen E., Verschraegen G. (2004) Wautersia gen. nov., a novel genus accommodating the phylogenetic lineage including Ralstonia eutropha and related species, and proposal of Ralstonia [Pseudomonas] syzygii (Roberts et al. 1990) comb. nov. Int. J. Syst. Evol. Microbiol. 54:317-327.

Volova T.G., Belyaeva O.G., Kalacheva G.S., Plotnikov V.F. (1996) Production and investigation of microbial heteropolymer polyhydroxyalkanoates. Doklady RAN (Articles of the Russian Academy of Sciences) 346:558-561 (in Russian).

Volova T.G., Kalacheva G.S., Konstantinova V.M., Puzyr A.P. (1992) Influence of growth conditions on polyhydroxybutyrate accumulation by hydrogen bacteria. Prikladnaya biokhimiya i mikrobiologiya (Applied biochemistry and microbiology) 28: 221-222 (in Russian). 
Volova T.G., Kalacheva G.S., Plotnikov V.F. (1998) Biosynthesis of heteropolymer polyhydroxyalkanoates by chemolithotrophic bacteria. Mikrobiologiya (Microbiology) 67:512-517 (in Russian).

Volova T.G., Kalacheva G.S., Altuhova O.V. (2002) Autotorophic synthesis of PHAs by Ralstonia eutropha in the presence of carbon monoxide. Appl. Microbiol. Biotechnol. 58: 675-678.

Wei Y., Jia Y., Tian J., Snell K.D., Müh U., Sinskey A.J., Lambalot R.H., Walsh C.T., Stubbe J.A. (2001) Class 1 and 111 polyhydroxyakanoate sythases from Ralstonia eutropha and Allochromatium vinosum: characterization and substrate specificity studies. Arch. Biochem. Biophys. 394:87-98.

Zavarzin G.A. (1972) Litotrofnyye mikroorganizmy (Lithotrophic microorganisms). Nauka, Moscow, 340 p. (in Russian).

Zhang S., Kolvek S., Goodwin S., Lenz R.W. (2004) Poly(hydroxyalkanoic acid) biosynthesis in Ectothiorhodospira shaposhnikovii: characterization and reactivity of a type III PHA synthase. Biomacromol. 5:40-48. 